\title{
Cancer Immunoprevention and Public Health
}

\author{
Sandeep K. Singh ${ }^{1}$ and Mehmet Tevfik Dorak ${ }^{2 *}$ \\ ${ }^{1}$ Department of Biological Sciences, Florida International University, Miami, FL, USA, ${ }^{2}$ School of Health Sciences, Liverpool \\ Hope University, Liverpool, UK
}

\section{OPEN ACCESS}

Edited by:

Dora ll'yasova,

Georgia State University, USA

Reviewed by:

Hongmei Wu,

Wenzhou Medical University,

China

Tony Kuo,

Los Angeles County Department

of Public Health, USA

Joe Leo Wiemels,

University of California at

San Francisco, USA

*Correspondence: Mehmet Tevfik Dorak dorakm@hope.ac.uk

Specialty section:

This article was submitted to

Epidemiology,

a section of the journal

Frontiers in Public Health

Received: 10 January 2017

Accepted: 18 April 2017

Published: 08 May 2017

Citation:

Singh SK and Dorak MT (2017) Cancer Immunoprevention and

Public Health.

Front. Public Health 5:101. doi: 10.3389/fpubh.2017.00101
The power of cancer immune surveillance has been documented beyond doubt, and the successful exploitation of immune response to cancer has started a new era in the war against cancer. Cancer biologists have recognized immunoevasion as an emerging hallmark in addition to the six hallmarks of cancer. Besides the natural connection between the immune system and cancer development, most established environmental risk factors are now known to interfere with immune surveillance mechanisms. Genetic variations regulating immunity may also modulate cancer susceptibility, but evidence for this is currently limited. Molecular cross talk linking "immune" and "genomic" surveillance pathways has been characterized. It appears that immune mechanisms may contribute to the effects of common cancer risk factors. We provide an updated overview of evidence for cancer immune surveillance, cancer risk factors interfering with it, and interventions to enhance cancer immune surveillance as tools to complement ongoing vaccine development efforts for cancer immunoprevention. Although there is a lot of support for cancer immunoprevention with simple lifestyle modifications from observational studies, there is an urgent need for clinical trials to establish the effectiveness of this approach for public health benefits.

\footnotetext{
Keywords: cancer prevention, cancer immunology, cancer immune surveillance, immunoprevention, public health, cancer risk factors
}

\section{INTRODUCTION}

Cancer is a major global public health issue. The global burden is continuing to increase and projected to reach 24 million in 2035 from 14 million new cases in 2012 (1). While major progress has been made in treatment, prevention remains to be the priority (1). Cancer prevention may benefit from the advances in cancer immunotherapy, which has led to the wider acceptance of the original idea of cancer immune surveillance. Indeed, the human body is not defenseless against cancer (2). The defense is provided by immune system and genomic surveillance mechanisms.

The original cancer immune surveillance concept was formulated almost half a century ago by Thomas (3) and Burnet $(4,5)$ [earlier studies are reviewed in Ref. (6-10)]. The cancer immune surveillance has now evolved into the cancer immunoediting concept (11), but for the exclusive consideration of cancer prevention, cancer immune surveillance is still a valid notion. The central theme of this idea was that an immune response can eliminate cells while they are still in the preclinical stages of transformation to overt cancer.

Given the prominent effect of immunotherapy in cancer treatment, and increasingly more widely accepted notion of cancer immune surveillance in cancer prevention (12-14), we explored potential connections between general cancer risk factors and immune capacity to examine 
whether the immune system may be a mediator for cancer risk. We also explored whether genetic epidemiology can be used as a probe for disease biology by checking genetic associations between immune system gene variant and cancer susceptibility. We review modifiable and non-modifiable lifestyle factors that influence the immune system and may be considered for cancer prevention.

\section{IMMUNE SYSTEM IS INSTRUMENTAL IN CANCER PREVENTION}

The relationship of the immune system to surveillance of cancer formation and treatment of clinical cancer has been extensively reviewed $(11,14-17)$. The evidence for cancer immune surveillance comes from animal studies, epidemiologic observations, and clinical observations.

\section{Animal Studies}

The original immune surveillance hypothesis was experimentally tested in a nude mice model in the 1970s by Stutman at Memorial Sloan Kettering Cancer Center in New York. The expectation was that immunodeficient (athymic nude) mice should develop more spontaneous and carcinogen-induced tumors than their immunocompetent counterparts. Stutman's experiments, however, did not yield results to validate these predictions $(18,19)$. Stutman's study concluded, correctly, that their results argued against the thymus dependency of immunologic surveillance (19). The nude mice model was good as a T-cell-deficient model, but it was later recognized that they still had active natural killer (NK) cells and, therefore, were not completely immunodeficient (20). These results resulted in shelving of the cancer immune surveillance hypothesis for a while until a new series of experiments provided strong support in the 1990s. It is now well documented that the immune system has a critical role in controlling the development of not only virally induced tumors but also non-virally induced tumors $(14,21,22)$.

In the modern experiments, when mice genetically engineered to be deficient for various components of the immune system were assessed for the development of carcinogen-induced tumors, it was observed that tumors arose more frequently and/ or grew more rapidly in the immunodeficient mice relative to immunocompetent controls. In particular, deficiencies in the development or function of CD8+ cytotoxic T lymphocytes (CTLs), CD4+ Th1 helper T cells, or NK cells each led to demonstrable increases in tumor incidence; moreover, mice with combined immunodeficiencies in both T cells and NK cells were even more susceptible to cancer development. The results indicated that, at least in certain experimental models, both the innate and adaptive cellular arms of the immune system are able to contribute significantly to immune surveillance and thus tumor eradication (23-25).

In addition, cancer cells from immunodeficient mice are not capable of initiating tumors in other immunocompetent hosts, but cancer cells from immunocompetent mice can initiate transplanted tumors in immunocompetent or immunodeficient hosts $(23,24)$. Such behavior has been interpreted as follows: highly immunogenic cancer cell clones are eliminated in immunocompetent hosts by the process of immunoediting with weakly immunogenic variants continuing to grow. Those weakly immunogenic cells giving rise to the tumor can also colonize other hosts both immunodeficient and immunocompetent. In immunodeficient hosts, however, the immunogenic cancer cells are not selectively eliminated and can survive the non-existing immunoediting process. When cells from tumors not subjected to immunoediting are transplanted into other genetically identical hosts, the immunogenic cancer cells are rejected by the competent immune systems of the new hosts (26).

When the host is immunocompetent and the tumor is immunogenic, cancer immune surveillance works most efficiently. This combination results in an active immune system as evident in the tumor microenvironment and also as systemic antibody response against the tumor antigens. Systemic response and its positive correlation with clinical outcome have been observed in colorectal cancer (antibodies against carcinoembryonic antigen), pancreas cancer [antibodies against mucin 1 (MUC1)], anaplastic large cell lymphoma (antibodies against anaplastic lymphoma kinase), and lung cancer (antibodies against zinc-binding $\alpha 2$ glycoprotein-1) (27). The constitution of the immune cells in the tumor microenvironment also correlates with clinical outcome. The stronger the tumor-specific immune response, the better the outcome $(14,16,21,27-32)$.

The modern experiments resulted in that a whole series of phases in the interaction of the immune system and cancer make up the "immunoediting" process. These phases are elimination, equilibrium, and escape $(11,17,33)$. Immunoediting process eliminates highly immunogenic tumors in their early phases and selects for less immunogenic ones allowing their escape from elimination. This happens both before (34) and after (35) treatment. It is the neoantigens derived from somatic mutations in tumors that provide the link between the adaptive immune system that mounts specific immune response and cancer elimination. The immunologic pressure against neoantigens is the reason for both immunological control (early) and escape from this control (late) in cancer development. Direct support for the immunoediting process also came from the observation that the more immunodeficient the host is, the more immunogenic their tumors are (17).

The immune system may also be a double-edged sword and act to induce or promote cancer via inflammation $(36,37)$. Either infection or autoimmunity-induced, or due to the lack of physical activity or obesity, chronic inflammation is a well-established risk factor for cancer development. Chronic inflammation is a feature of aging and increases the risk for cancer development, progression, and metastasis by generating a tumor-supporting microenvironment. Inflammation is recognized as a factor that fosters multiple cancer hallmark functions (38). Cancer's abilities to thrive in a chronically inflamed microenvironment, evade immune recognition, and suppress immune reactivity are also named as three immune hallmarks of cancer (39).

\section{Epidemiologic Observations}

Epidemiologic studies have provided strong evidence for the control of cancer formation and control by the immune system. The earliest observation was that people with a weakened immune 
system have higher cancer incidence rates. At least some of primary immunodeficiencies confer increased cancer risk $(8,40)$. Acquired immunodeficiencies or immunosuppression as happens in organ transplant recipients and HIV infection has increased risk for cancer $(8,41,42)$. Although earlier studies only observed an increased risk for infection-related cancers, later and larger studies show an increased risk for non-infection-related cancers (42). Some immunosuppressed organ transplant recipients have been observed to develop donor-derived cancers, suggesting that in the ostensibly tumor-free donors, the cancer cells were held in check, in a dormant state, by a fully functional immune system (43). These observations provide examples for the elimination phase of the modern immunoediting process.

There is also evidence for the equilibrium phase. A convincing number of studies on people died of non-cancer causes have revealed a high degree of occult cancers in otherwise healthy individuals (44). Few specific examples are as follows: in 110 consecutive autopsies of women aged 20-54 years, 22 were found to have evidence of breast cancer (only 1 had a history of cancer). Of these, $45 \%$ had multifocal and $41 \%$ had bilateral evidence for cancer presence (45). Another study noted the presence of cancer in opposite breast in $80 \%$ of women who died with a clinical diagnosis of breast cancer (46).

Unexpectedly high in situ prostate cancer rates were also found in men. An evaluation of 152 prostate glands from young males aged $10-49$ years, up to $44 \%$ of them (in the fifth decade of age) had microscopic evidence of prostate cancer with an increasing agerelated incidence (47). In Hungary, incidental prostate cancer was found in $38.8 \%$ of 139 men aged $18-95$ years, and there was also an age-related increase (48). A larger study examined 340 prostates harvested from organ donors and detected adenocarcinoma in $12 \%$ of them also with an age-dependent increase, leading to 1 in 3 chance of carrying incidental cancer in the 60- to 69-year-old age group and even higher (46\%) in 70- to 81-year-old men (49). One study compared incidental prostate carcinoma rates between Russian $(n=220$; mean age $=62.5$ years $)$ and Japanese $(n=100$; mean age $=68.5$ years) men in autopsy samples. Prostate cancer was detected in $37.3 \%$ of Russian and in $35.0 \%$ of Japanese men overall, with the cancer rates reaching more than $40 \%$ of men aged greater than 60 years and nearly $60 \%$ in men aged above 80 years (50). The prevalence of latent prostate cancer is well above $2.9 \%$ lifetime risk of dying from prostate cancer (51).

The autopsy findings in breast and prostate cancers suggest that our bodies harbor many more cancers than those become clinically evident [so-called cancer without disease (52)]. One way to interpret this observation is that most tumors are kept at equilibrium by the immune system. This interpretation also applies to the finding that pancreas cancer takes more than two decades to become metastatic and detectable (53). A similar phenomenon is reported for dormant melanoma in the mouse in which it was established that tumor cells disseminate early, but immunosurveillance limits metastatic outgrowth (54). There are, however, alternative interpretations involving angiogenesis pathways (52, 55). Thus, the reasons for the observations of dormant cancers at frequencies much higher than actual cancer incidence rates may include immune control, but this has not been specifically examined. Tumor dormancy as a result of endogenous immune surveillance is better documented for metastatic cells $(54,56)$, but there is currently no direct evidence for the role of the immune system in restriction of primary tumor growth in humans. This is, therefore, an area where future research may shed some light.

Clinical epidemiology also increasingly supports the existence of anticancer immune responses in some forms of human cancer $(14,16,21,27,29-32)$. For example, patients who have cancer, especially colon and ovarian cancers, and who are heavily infiltrated with CTLs and NK cells have a better prognosis than those who lack such abundant killer lymphocytes.

Epidemiologic studies also suggested that otherwise healthy people with lower immune-mediated NK cell-mediated cytotoxic capacity develop more cancers in follow-up, and there is a genetic component in this correlation $(57,58)$. This is just additional evidence that NK cells play a critical role in the recognition and eradication of tumors (59). In experimental animal models, NK cell deficiency increases cancer occurrence just like observed in Chediak-Higashi syndrome characterized by abnormal NK cytotoxic function. Importantly, natural cytotoxicity correlates with lifestyle factors known to modify cancer susceptibility $(60,61)$. Among the statistically significant observations, smoking (negative effect on NK cell activity), green vegetable consumption, and regular sleeping (positive effect) (60) as well as personality types (61) were noteworthy. A separate study reported favorable effect of beta-carotene on NK cell function in the elderly (62).

\section{Clinical Observations}

The strongest evidence for cancer immune surveillance comes from the incredible success of cancer immunotherapy, which has revolutionized cancer treatment. The Science magazine named cancer immunotherapy as the Breakthrough of the Year for 2013 (63). Besides cancer immunotherapy becoming a routine treatment choice, there are more than a dozen drugs or vaccines approved by the US Food and Drug Administration for cancer prevention (64). Cancer immunoediting, beginning with cancer immune surveillance and elimination and ending with escape, is now firmly established as a reality. As a result, escape from immune control (immunoevasion) is now one of the emerging hallmarks of cancer (38).

The success of immunotherapy comes from its ability to break down the immunoevasion caused by the tumor cells. Tumor cells interfere with the immune response against tumor antigens by releasing molecules, which are normally used by the immune system to self-limit the activation. Once the antigen receptors (T-cell receptors) are engaged with the antigen, in this case tumor antigen, T-cells also require an activation signal from the costimulatory molecule CD28 to become effective killer cells. It is the $\mathrm{B} 7$ molecule on the antigen-presenting cell that activates the costimulatory molecule CD28 on T cells. T cell activation is required for immune response but should be controlled to avoid overactivation and autoimmunity. Once activated, T cells start expressing coinhibitory immune checkpoint molecules, cytotoxic T lymphocyte-associated antigen 4 (CTLA-4), and programmed death 1 (PD-1) (65). Engagement of these molecules with B7 generates inhibitory signals for $\mathrm{T}$ cells. Tumor cells inhibit $\mathrm{T}$ cells and evade immune response against them by releasing such 
coinhibitory molecules. For the purpose of cancer immunotherapy, monoclonal antibodies have been generated to counter these inhibitory signals. This is achieved by "immune checkpoint blockade" of CTLA-4, PD-1, or PD-1 ligand (PD-L1). These are monoclonal antibodies known as ipilimumab (an inhibitor of CTLA-4), nivolumab and pembrolizumab (inhibitors of PD-1), and atezolizumab and durvalumab (inhibitors of PD-L1) (65). The success of these immune check point blockers is strong evidence for the involvement of the immune system in the control of cancer development.

Another clinical observation is that agents used in cancer prevention or treatment may stimulate the immune system. This is likened to "the invisible arm of immunity" acting alongside their cytotoxic effects. The chemoprevention agents such as repurposed drugs such as aspirin, COX-2 inhibitors (e.g., celecoxib), the antidiabetic agent metformin, the bisphosphonate zoledronic acid, and tamoxifen (and aromatase inhibitors) used in cancer prevention also show immune activity [reviewed in Ref. $(32,66)]$. Another more experimental chemopreventive agent curcumin also has immunologic effects $(32,67)$. Likewise, the antitumor effects of many conventional cancer treatments also involve the immune system. They promote immunogenic tumor cell death or directly stimulate immunoeffector cells $(27,31,32,68)$. The immunologic effects include enhancing the antigen-presenting cell (mainly dendritic cells) activity and cross-presentation of tumor antigens to CD8+ T-cells (e.g., methotrexate), increasing HLA class I antigen expression (e.g., gemcitabine, oxaliplatin, cyclophosphamide), favorable modification of helper T-cell polarization, and inhibition of immuno suppressor cells [mainly FOXP3+ T regulatory (Treg) cells, and myeloid-derived suppressor cells (MDSCs)] (e.g., vincristine, docetaxel, paclitaxel) $(16,32)$. These observations even led to a new form of cancer treatment using low doses of conventional chemotherapeutic agents (metronomic chemotherapy) to stimulate the immune system as opposed to suppressing as they do at their usual doses (27). In fact, methotrexate is such a strong immunosuppressive so that it is also used to treat autoimmune disorders but is used as an immunostimulant at lower doses.

\section{MOST CANCER RISK FACTORS OPERATE VIA THE IMMUNE SYSTEM}

\section{Environmental Risk Factors Age and Sex}

Age is one of the strongest risk factors for cancer development. It is reported that the mortality rate increases 43 times for cancer in people older than 65 years in Western countries (69). An examination of the US SEER Database (2009-2013) shows that the median age at diagnosis for all cancers is 65 years, and median age at death from cancer is 72 years (https://seer.cancer. gov/statfacts/html/all.html). Cancer occurs more frequently with increasing age due to cumulative exposures to carcinogenic agents such as tobacco, infectious agents, and chemicals, as well as due to physiologic changes in the body due to hormonal changes and immune system dysregulation. Among the physiologic changes, immunosenescence, which can be described as progressive decline of the immune functions, alongside qualitative and quantitative dysregulations involve both innate and adaptive arms of immunity $(12,70-74)$. Some of the consequences of immunosenescence with aging like reactivation of persistent viral infections (such as varicella zoster virus) are well recognized. Conversely, it is the persistent viral and parasitic infections that contribute to the loss of immunosurveillance via premature exhaustion of $\mathrm{T}$ cells (70). Overall, infections, cancer, and autoimmune diseases are more frequent in the elderly, and all are related to the changes in the immune system $(71,73)$. Most crucially, bone marrow hematopoietic stem cells skew toward myelopoiesis (and against lymphopoiesis) with age, which leads to increased numbers of MDSCs $(73,75)$. The increase in MDSC numbers show correlations with cancer incidence in the elderly $(73,75)$. Certain lifestyle factors may potentially contribute to age-associated unfavorably changes in immunity in the elderly, including psychosocial parameters, stress responsiveness, physical inactivity, and nutritional factors (76). Some of the age-related immune system changes in the elderly may be reversed by simple lifestyle modifications (76, 77), including aerobic exercise (78), which is further discussed below. Further, a lot of pharmacologic ways to rejuvenate the aging immune system are also present $(72,79)$, but none is in current routine use yet.

Sex is another consistent risk factor for cancer $(80,81)$. Sex effect is likely to operate through immune surveillance differences between the sexes $(12,82)$. Thus, like age, sex is another consistent risk factor that seems to operate via the immune system.

\section{Lack of Physical Activity}

Health benefits of regular and moderate intensity physical activity are not restricted to improvements in metabolic and cardiorespiratory function for prevention of type 2 diabetes and cardiovascular diseases. Physical activity also decreases the risk for various cancers by several mechanisms, including decreased sex hormones, metabolic hormones and inflammation, and quantitative and qualitative changes in immune cells $(77,83)$. Research on the effect of aerobic exercise on the immune response has confirmed the skeletal muscle as an endocrine organ capable of secreting cytokines, which are called "myokines." Exercise modulates the host immune response via skeletal muscle-organ cross talk (84-86). Regular physical activity appears to have immunoenhancing effects via improved neutrophil microbicidal functions, which reduce the risk of infectious disease, and increased immune cell telomere length $(77,78,87)$. Negative energy balance induced by exercise also exerts anti-inflammatory effects by reducing chronic lowgrade inflammation $(77,88)$. Overall, the evidence for a causal association between physical activity and colon and breast cancers is strongest and somewhat weaker for prostate, lung, and endometrial cancers and insufficient for testicular and ovarian cancers $(89,90)$. As a result, more breast and colon cancers than coronary heart disease can be prevented by regular physical activity $(90,91)$. It has been estimated that up to 330,000 cases of 6 major cancers could have been prevented with regular physical activity at the recommended level in Europe in 2008 (90). 


\section{Obesity}

Obesity is responsible up to $20 \%$ of cancer mortality (92). Both local and systemic mechanisms are involved in the mediation of increased cancer risk, and these include the immune system alterations associated with obesity (12). Like the muscle is now considered an organ, the adipose tissue is an active endocrine organ, and like myokines from the muscle, adipokines are released from the fat tissue, which target organs including the immune system $(93,94)$. Overall effects of obesity on the immune system can be summarized as direct negative effect of the major adipokine leptin on immune cells; induction of chronic systemic inflammation via secretion of pro-inflammatory adipokines; acceleration of the aging of thymus, an important immune system organ; adversely affect the function of the primary immune organs bone marrow and thymus via infiltration of fat tissue; and reduced immune response to infectious agents (12). In particular, the involution of the thymus with age and lower production of naive $\mathrm{T}$ cells contribute to lower immune surveillance in the elderly. It has been shown that obesity accelerates thymic involution resulting in lower $\mathrm{T}$ cell numbers (95). Therefore, obesity is another cancer risk factor that acts, among other mechanisms, through alterations it causes in the immune system.

\section{Diet}

The influence of dietary factors in the development of chronic diseases, including cancer, is well known. What is not that well known is the role of diet in predisposition to cancer via immune system modulation and anti-inflammatory effects (96). Candidate nutrients with immunomodulatory effects include essential fatty acids; antioxidants; calcium; zinc; selenium; vitamins A, D, B6, and folate; omega-3 polyunsaturated fatty acids (omega-3 PUFAs); glutamine; arginine; S-amino acids; nucleotides; polyphenols; epigallocatechin gallate; beta-glucans; isothiocyanates; curcumin; and probiotics, which make up immunonutrient mixes (96-98). Caloric restriction and protein calorie balance have also been reported to have some immunomodulatory effects. Unfortunately, despite some data from observational and animal studies, there are only limited data from randomized clinical trials (RCTs). A cohort study examined the effects of high marine omega-3 PUFAs intake on colon cancer occurrence and clinical status and reported a very favorable outcome with detectable improvement on the immune response to the tumor (99). A double-blind RCT explored the effectiveness of a commercially available immunomodulating enteral nutrition formula (Impact ${ }^{\circledR}$, Nestlé) in radiochemotherapy-treated head and neck and esophageal cancer patients (100). By phenotyping, functional assays, and gene expression analysis, clear immunostimulation was noted although clinical correlates were not reported. Most interestingly, even cancer preventing effect of fiber may be due to its indirect effect on the immune system. High-fiber diet consisting of starch, cellulose, pectin, or fructan induce the gut microbiota to produce short-chain fatty acid metabolites (acetate, butyrate, propionate), which in turn stimulate Treg cells for expansion and immune-suppressive properties to control pro-inflammatory responses in the gut (101). Clinical correlates of this observation are yet unknown, but high-fiber diet may have an immunomodulatory component in its cancer preventive effects.

\section{Smoking}

Smoking and cancer connection is well established and is due to the carcinogenic content of tobacco products. The overall effects of smoking on the immune system is to weaken the immune system via a pro-inflammatory reaction and suppression of effector functions of immune cells as well as skewing of the immune response toward Th2 type (102) although the effect on cytokine production seems negligible (103). Cytotoxic $\mathrm{T}$ cells, NK cells, and macrophages are among important immune cells that are suppressed by smoking. It is probable that immune system alterations complement smoking-associated carcinogenic and mutagenic effects in the causal pathway to cancer development.

\section{Childhood Infections and Future Cancer}

Recurrent infections may show seemingly inconsistent correlations with future cancer risk. If recurrent infections are due to immunodeficiency, childhood cancer risk may be increased as a result of insufficient immune surveillance (104), but if they are community-acquired natural infections, these infections may help development of the immune system and subsequently prevent childhood cancer development (105). An abnormal immune response by an underdeveloped immune system to a common infection because of a delay in infectious exposure is also a possibility (106), which is known as the Greaves hypothesis proposed to explain the childhood leukemia occurrence most commonly in the age peak (2-5 years old).

The more interesting observations concern the lower risk of adult cancer following certain childhood infections (12). It has been observed that infections such as chicken pox, measles, pertussis, and mumps may lower the risk for a number of adult cancers, especially ovarian cancer $(107,108)$. This is attributed to molecular mimicry in which microorganisms causing these infections have certain antigens (such as MUC1) that induce a lifelong immunity, which then recognizes the same antigen on cancer cells. The preexisting immunity against tumor antigens due to cross-reactivity facilitates immune surveillance, and cancer would be prevented. An altered form of the tumor antigen MUC1 is frequently expressed in ovarian cancer, and immunity against MUC1 is formed by mumps infection, which results in the observed inverse correlation between mumps and ovarian cancer $(107,108)$. It is now a possibility that upward trends in cancer incidence may be contributed by the mass vaccination campaigns and fewer infectious episodes in childhood.

\section{Reproductive Factors}

Nulliparity is a strong and consistent risk factor for breast, ovarian, and endometrial cancers, whereas early full-term pregnancy and parity confer a significant protection. The mechanism is thought to involve local hormonal effects on these organs, but there appears to be an immune system involvement too (12). Comparative molecular studies in breast tissue have shown that the gene expression signature differences between nulliparous and multiparous women as well as between pregnancy and 
postpregnancy included those of immune surveillance genes $(109,110)$. It has also been proposed that pregnancy increases the exposure of women to fetal antigens and induces immunity against them, which may be targeted against cancers expressing fetal antigens (111). Equally, a greater number of ovulatory cycles increase the risk for ovarian, breast, endometrial, pancreas, and colon cancers and correlate with lower anti-MUC1 antibodies (107).

\section{Other Environmental Cancer Risk Factors}

Other connections of the immune system to cancer risk factors include pesticides (112), benzene (113), arsenic (114), ultraviolet irradiation (115) exposure, and psychological stress (116, 117).

\section{Genetic Risk Factors}

Genetic variation is instrumental as the origin of variation observed in many traits. Formally, the contribution of heritable genetic variation to the phenotypic variance observed is measured by heritability, which lies between 0 and 100\%. Heritability can be quantified in twin studies. Such a study of immune parameters concluded that heritability was less than $20 \%$, and a great majority of examined parameters $(>75 \%)$ were dominated by non-heritable, i.e., environmental, influences (118). Another twin study examined 78,000 immune traits of which 1,800 were independent and were subjected to a genome-wide search for genetic correlates (119). We have subjected known genetic markers of immune parameters $(119,120)$ to a cross examination against the existing genome-wide association studies (GWAS) result databases to see whether any of them is a cancer risk marker. As shown in Table 1, this effort only revealed very weak cancer associations in
GWAS. When we repeated the same analysis with immunoregulatory gene SNPs reported to be associated with cancer risk in candidate gene studies, we observed stronger GWAS associations although not replicating the originally observed associations (Table 1). Thus, we could only obtain limited evidence for the involvement of immune system-related genetic polymorphisms in the modification of cancer risk. This result is not necessarily surprising given that GWAS cannot readily capture gene-gene or gene-environment interactions (121), which are probably more relevant to the immune system. Since most cancers result from the combined effects of environmental factors and inherited susceptibilities and that only a few cancers are "solely" of genetic origin. The importance of the environment in cancer causation has implications for studies of genetic risk in cancer that is not sufficiently appreciated (122).

Cumulative evidence for immune surveillance against the development of cancer and for the control of existing cancer is listed in Table 2.

\section{IMMUNOPREVENTION OF CANCER AS A PUBLIC HEALTH INTERVENTION}

An immunologic approach to cancer prevention is not new (128). Most of the general cancer prevention approaches including elimination of environmental hazards (e.g., smoking), lifestyle changes (e.g., increased physical activity, healthy and balanced diet with green vegetables), chemopreventive agents in high-risk individuals, and obviously immunoprevention via vaccination [e.g., hepatitis B virus (HBV) and human papilloma virus (HPV) vaccination] target the immune system at least partially.

TABLE 1 | Immune regulatory gene polymorphisms and cancer susceptibility in GWAS and GRASP catalogs.

\begin{tabular}{|c|c|c|c|}
\hline Genetic variants & Main non-cancer associations & Cancer associations & $\begin{array}{c}\text { Reference } \\
\text { [PubMed ID } \\
\text { number (PMID)] }\end{array}$ \\
\hline $\begin{array}{l}\text { Genetic variants regulating immune } \\
\text { cell levels }^{\text {b }}\end{array}$ & $\begin{array}{l}\text { Autoimmune disorders (type } 1 \\
\text { diabetes, rheumatoid arthritis) }\end{array}$ & Neuroblastoma (rs6547705; $P=2.0 \mathrm{E}-02$ ) & 21124317 \\
\hline $\begin{array}{l}\text { Genetic variants correlated with } \\
\text { immune traits }{ }^{c}\end{array}$ & $\begin{array}{l}\text { Autoimmune disorders (ulcerative } \\
\text { colitis); hemoglobin A2 level }\end{array}$ & $\begin{array}{l}\text { Neuroblastoma (rs10917750; } P=5.8 \mathrm{E}-04-\mathrm{rs} 723177 \\
P=9.6 \mathrm{E}-04-\mathrm{rs} 4657090 ; P=1.2 \mathrm{E}-03-\mathrm{rs} 1934908 ; P=3.8 \mathrm{E}-03) \\
\text { Prostate cancer (rs12359272; } P=8.2 \mathrm{E}-03)\end{array}$ & $\begin{array}{l}21124317 \\
23668334\end{array}$ \\
\hline \multirow{10}{*}{$\begin{array}{l}\text { Immunoregulatory gene variants } \\
\text { associated with cancer risk in } \\
\text { candidate gene studies }^{d}\end{array}$} & \multirow{10}{*}{$\begin{array}{l}\text { Autoimmune disorders (rheumatoid } \\
\text { arthritis, Crohn disease) }\end{array}$} & Non-melanoma skin cancer (rs12203592; $P=7.2 \mathrm{E}-14)$ & 23548203 \\
\hline & & Melanoma (rs12203592; $P=2.5 \mathrm{E}-05)$ & 20602913 \\
\hline & & Neuroblastoma (rs12203592; $P=4.9 \mathrm{E}-05)$ & 21124317 \\
\hline & & Breast cancer (rs12203592; $P=2.7 \mathrm{E}-06)$ & 20453838 \\
\hline & & Hodgkin lymphoma (rs2395185; $P=4 \mathrm{E}-31)$ & 22286212 \\
\hline & & Lung cancer (rs2395185; $P=9.5 \mathrm{E}-10)$ & 23143601 \\
\hline & & Acute lymphoblastic leukemia (rs17007695; $P=9 \mathrm{E}-07)$ & 19176441 \\
\hline & & Childhood acute lymphoblastic leukemia (rs5742909, $P=8 \mathrm{E}-04)$ & 20189245 \\
\hline & & Breast cancer (rs2296135, $P=3.7 \mathrm{E}-03$ ) & 23468962 \\
\hline & & Non-Hodgkin lymphoma (rs1041981; $P=1.9 \mathrm{E}-02)$ & 21471979 \\
\hline
\end{tabular}

aFor cancer associations shown (PMID).

${ }^{b}$ Ref. (120) (SNPs listed in Supplementary Tables 5 and 6 in the original paper, $n=109$. The SNP list is available in Table S1A in Supplementary Material in the present paper). ${ }^{\circ}$ Ref. (119) (SNPs listed in Table 1/Supplementary Table 5 with $P<5 E-10$ in the original paper; $n=709$. The SNP list is available in Table S1B in Supplementary Material in the present paper).

${ }^{d}$ The SNPS included in the analysis here are listed in Table S1C in Supplementary Material. 
TABLE 2 | Evidence for immune surveillance against the development of cancer and for the control of existing cancer.

\begin{tabular}{|c|c|c|}
\hline Observation & Implication & Reference ${ }^{a}$ \\
\hline $\begin{array}{l}\text { Immunodeficient animals and } \\
\text { humans developing more cancers; } \\
\text { immunosuppression causing an } \\
\text { increase in cancer incidence }\end{array}$ & $\begin{array}{l}\text { Control of cancer } \\
\text { development by the } \\
\text { immune system }\end{array}$ & $\begin{array}{c}(8,40,42 \\
123)\end{array}$ \\
\hline $\begin{array}{l}\text { Increased risk for cancer in people with } \\
\text { lower natural cytotoxic activity in their } \\
\text { peripheral blood }\end{array}$ & $\begin{array}{l}\text { Control of cancer } \\
\text { development by the } \\
\text { immune system }\end{array}$ & $(57,58)$ \\
\hline $\begin{array}{l}\text { A high percentage of occult cancers in } \\
\text { autopsy studies }\end{array}$ & $\begin{array}{l}\text { Control of cancer at } \\
\text { the preclinical stage } \\
\text { by the immune system } \\
\text { (equilibrium) }\end{array}$ & $(44-50)$ \\
\hline $\begin{array}{l}\text { Decades long time taken by pancreas } \\
\text { cancer to become clinically overt }\end{array}$ & $\begin{array}{l}\text { Control of cancer at the } \\
\text { preclinical stage by the } \\
\text { immune system }\end{array}$ & (53) \\
\hline $\begin{array}{l}\text { Control of occult cancer at the } \\
\text { equilibrium phase by adaptive immune } \\
\text { system }\end{array}$ & $\begin{array}{l}\text { Control of cancer at the } \\
\text { preclinical stage by the } \\
\text { immune system }\end{array}$ & $(124,125)$ \\
\hline $\begin{array}{l}\text { Development of donor-derived } \\
\text { malignancies that have been kept } \\
\text { under control in immunosuppressed } \\
\text { transplant recipients }\end{array}$ & $\begin{array}{l}\text { Control of cancer at the } \\
\text { preclinical stage by the } \\
\text { immune system }\end{array}$ & (43) \\
\hline $\begin{array}{l}\text { More immunogenic tumors developing } \\
\text { in more immunodeficient animals }\end{array}$ & $\begin{array}{l}\text { Elimination of } \\
\text { immunogenic tumors } \\
\text { by immune competent } \\
\text { hosts }\end{array}$ & $(17,124,126)$ \\
\hline $\begin{array}{l}\text { Cancer patients with antibodies } \\
\text { against antigens of their tumors (e.g., } \\
\text { carcinoembryonic antigen, mucin 1) } \\
\text { having a better clinical outcome and } \\
\text { even spontaneous regression }\end{array}$ & $\begin{array}{l}\text { Existent antitumor } \\
\text { immunity exerting a } \\
\text { favorable effect on the } \\
\text { outcome }\end{array}$ & $(27,31,127)$ \\
\hline $\begin{array}{l}\text { Successful chemopreventive agents } \\
\text { (aspirin, metformin, tamoxifen, } \\
\text { bisphosphonate) having immune } \\
\text { enhancing effects }\end{array}$ & $\begin{array}{l}\text { Contribution of the } \\
\text { immune system to the } \\
\text { preventive effects }\end{array}$ & $(32,66)$ \\
\hline $\begin{array}{l}\text { Successful cancer chemotherapeutic } \\
\text { agents having immune modulatory } \\
\text { effects favorable for anticancer } \\
\text { immunity }\end{array}$ & $\begin{array}{l}\text { Contribution of the } \\
\text { immune system to the } \\
\text { therapeutic effects }\end{array}$ & $\begin{array}{c}(27,31,32 \\
68)\end{array}$ \\
\hline $\begin{array}{l}\text { The composition of tumor-infiltrating } \\
\text { immune cells and indicators of immune } \\
\text { system activity correlate with the } \\
\text { clinical outcome }\end{array}$ & $\begin{array}{l}\text { Existent antitumor } \\
\text { immunity exerting a } \\
\text { favorable effect on the } \\
\text { outcome }\end{array}$ & $\begin{array}{c}(14,16,21 \\
27-32)\end{array}$ \\
\hline
\end{tabular}

aln some instances, review papers rather than primary references are cited.

Specifically, immunoprevention aims to prevent cancers through the use of vaccines against carcinogenic viruses and tumor antigens, antibodies against immune molecules, and immune modulators (30). While vaccines against tumor antigens and antibodies are used in individuals with a specific cancer, immune modulators have more broad activities to enhance natural cancer immune surveillance. HBV and HPV vaccinations are approved interventions against liver and cervical cancer caused by these viruses, respectively. Pharmacologic immune modulators that are currently in use include aspirin, COX-2 inhibitors, aromatase inhibitors, metformin, and bisphosphonates (32). Non-pharmacologic effects linked to lifestyle factors and environmental exposures reviewed in this article may have a wider application in primary prevention in people who do not yet have cancer. In fact, now that cancer is becoming the most common cause of death in developed nations (129), and it is important to increase awareness about immunoenhancement and cancer immunoprevention for everyone's benefit (78).

Immunoenhancement is a very active area of research (76-78, 87 ) with some emerging results (128). Among the non-pharmacologic interventions to enhance the immune system, physical activity, dietary factors, and lifestyle changes are the best-known ones, and the use of immune modulation for prevention rather than therapy is becoming a reality (128).

Regular moderate physical activity is the most effective prevention strategy for a number of chronic diseases. Despite being very affordable, it is probably the most underutilized intervention. While the impact of physical activity on cardiovascular system is well recognized and a lot of interventions are implemented to enhance cardiovascular health, its connection to the immune enhancement and cancer prevention is not known as much. This is despite that the impact is actually greater on cancer prevention although this is not exclusively due to immune-enhancing effects $(90,91)$. Despite calls for exercise clinical trials in cancer prevention research $(130,131)$, more progress has been recorded in clinical trials on the effect of exercise on clinical outcome and survivorship of cancers than their prevention $(132,133)$. Since the evidence is strongest for colon and breast cancers $(89,90)$, at least for these ones, the modulation of the immune system with an exercise program may be used to enhance prevention and treatment outcomes (86). As mentioned above, physical activity is also effective in reversing age-related deterioration in the immune system (78). Typically, as we age, physical activity levels decline. Among the reasons for this are the lack of motivation for physical activity and unawareness of the health benefits, while awareness of unhealthy lifestyle, perceived susceptibility to disease as well as motivation towards lifestyle changes are important mediators of participation in lifestyle interventions (134).

After physical activity, nutritional modifications have the strongest immunomodulatory effects that may be used as a public health intervention (78). Flavonoids (such as green tea) are well known for their cancer preventive properties, which are due to epigenetic modifications (135). Quercetin, for example, is proposed as a preventive dietary factor for melanoma (136), and green tea is an acknowledged cancer preventive agent in Japan (137). A positive effect of all flavonoids is modulation of the immune system (138). Thus, flavonoids, including green tea, can be considered as safe cancer immunopreventive agents for general use. Fiber- and green vegetable-rich diet is also safe for general use for their cancer preventive properties, which include immune enhancement. Dietary supplements mentioned above, including beta-carotene and vitamin E, are suggested as immunomodulatory agents, but confirmatory evidence from clinical trials is currently missing. Until then, the recommendation of the American Institute for Cancer Research of not to take any supplements for cancer prevention should be adhered to.

Although RCTs are regarded as the source of strongest evidence to support clinical decisions, increased trial complexity and cost may be inhibitory and may explain the scarcity of such 
trials in cancer immunoprevention studies. Recently popularized pragmatic clinical trials represent a new approach for enhancing the evidence base by relaxing the strict regulations governing RCT conduct $(139,140)$. These trials are more widely accessible by participants, are less resource intensive, and place minimal burden on participants. Pragmatic trials are designed to test the effectiveness of usually non-pharmacologic intervention in routine practice and whether an intervention actually works in real life. They, therefore, generate evidence with a greater external validity. Besides pragmatic trials, other more practical approaches such as systems science methods are also available as alternatives and have already been used to answer important public health science questions (141). Thus, implementation of cancer immunopreventive strategies as public health interventions may be expedited using research methods emerging as alternatives to RCTs.

While cancer immunotherapy has revolutionized cancer treatment, cancer immunoprevention using vaccines and chemopreventive agents for selected high-risk people is also moving into the clinics $(1,66)$. Recent technological developments herald a new era in cancer detection and management that will also necessitate public health interventions. Soon, there will be more people under active surveillance than ever before, and recommendations to these people may include lifestyle modifications to maintain a healthy immune system as well as personalized risk stratification based on the assessment of their immune system. Preventing cancer in otherwise healthy, asymptomatic, and unsuspecting people will need to be carefully considered. If lifestyle modifications to enhance immune surveillance to prevent cancer sounds like a far-fetched idea, one has to remember the recent success stories

\section{REFERENCES}

1. Stewart BW, Bray F, Forman D, Ohgaki H, Straif K, Ullrich A, et al. Cancer prevention as part of precision medicine: 'plenty to be done'. Carcinogenesis (2016) 37(1):2-9. doi:10.1093/carcin/bgv166

2. Klein G, Imreh S, Zabarovsky ER. Why do we not all die of cancer at an early age? Adv Cancer Res (2007) 98:1-16. doi:10.1016/S0065-230X(06)98001-4

3. Thomas L. Reactions to homologous tissue antigens in relation to hypersensitivity. In: Lawrence HS, editor. Cellular and Humoral Aspects of the Hypersensitive States. New York, NY, USA: Hoeber-Harper (1959). p. 529-33.

4. Burnet M. Cancer; a biological approach. I. The processes of control. Br Med $J$ (1957) 1(5022):779-86. doi:10.1136/bmj.1.5022.779

5. Burnet FM. The concept of immunological surveillance. Prog Exp Tumor Res (1970) 13:1-27. doi:10.1159/000386035

6. Schwartz RS. Another look at immunologic surveillance. N Engl J Med (1975) 293(4):181-4. doi:10.1056/NEJM197507242930406

7. Klein G. Immune surveillance - a powerful mechanism with a limited range. Natl Cancer Inst Monogr (1976) 44:109-13.

8. Schwartz RS. Immunodeficiency, immunosuppression, and susceptibility to neoplasms. J Natl Cancer Inst Monogr (2001) 28:5-9. doi:10.1093/oxfordjournals.jncimonographs.a024257

9. Smyth MJ. Immune system vs cancer. Scientist (2009) 23(11):36-41.

10. Ribatti D. The concept of immune surveillance against tumors. The first theories. Oncotarget (2017) 8(4):7175-80. doi:10.18632/oncotarget.12739

11. Mittal D, Gubin MM, Schreiber RD, Smyth MJ. New insights into cancer immunoediting and its three component phases - elimination, equilibrium and escape. Curr Opin Immunol (2014) 27:16-25. doi:10.1016/j. coi.2014.01.004

12. Cramer DW, Finn OJ. Epidemiologic perspective on immune-surveillance in cancer. Curr Opin Immunol (2011) 23(2):265-71. doi:10.1016/j. coi.2011.01.002 in cardiovascular disease prevention by the same approach (142). Cancer-related mortality is beginning to exceed cardiovascular disease-related mortality in some European countries (143) and US states (129), and primary prevention is the most effective way to fight cancer (144). With more than $50 \%$ of cancers are hypothetically preventable through lifestyle modifications (145), the aim should be to increase this proportion with the implementation of cancer immunoprevention strategies in the near future.

\section{AUTHOR CONTRIBUTIONS}

Substantial contributions to the conception or design of the work, drafting the work or revising it critically for important intellectual content, and agreement to be accountable for all aspects of the work in ensuring that questions related to the accuracy or integrity of any part of the work are appropriately investigated and resolved: MD, SS; the acquisition, analysis, or interpretation of data for the work: SS; and final approval of the version to be published: MD.

\section{ACKNOWLEDGMENTS}

We apologize to the investigators whose research could not be cited directly due to space limitations.

\section{SUPPLEMENTARY MATERIAL}

The Supplementary Material for this article can be found online at http://journal.frontiersin.org/article/10.3389/fpubh.2017.00101/ full\#supplementary-material.

13. Michaud DS, Houseman EA, Marsit CJ, Nelson HH, Wiencke JK, Kelsey $\mathrm{KT}$. Understanding the role of the immune system in the development of cancer: new opportunities for population-based research. Cancer Epidemiol Biomarkers Prev (2015) 24(12):1811-9. doi:10.1158/1055-9965. EPI-15-0681

14. Corthay A. Does the immune system naturally protect against cancer? Front Immunol (2014) 5:197. doi:10.3389/fimmu.2014.00197

15. Swann JB, Smyth MJ. Immune surveillance of tumors. J Clin Invest (2007) 117(5):1137-46. doi:10.1172/JCI31405

16. Disis ML. Immune regulation of cancer. J Clin Oncol (2010) 28(29):4531-8. doi:10.1200/JCO.2009.27.2146

17. Schreiber RD, Old LJ, Smyth MJ. Cancer immunoediting: integrating immunity's roles in cancer suppression and promotion. Science (2011) 331(6024):1565-70. doi:10.1126/science.1203486

18. Stutman O. Tumor development after 3-methylcholanthrene in immunologically deficient athymic-nude mice. Science (1974) 183(4124):534-6. doi:10.1126/science.183.4124.534

19. Stutman O. Chemical carcinogenesis in nude mice: comparison between nude mice from homozygous matings and heterozygous matings and effect of age and carcinogen dose. J Natl Cancer Inst (1979) 62(2):353-8.

20. Stutman O. Natural antitumor resistance in immune-deficient mice. Exp Cell Biol (1984) 52(1-2):30-9.

21. Bindea G, Mlecnik B, Fridman WH, Pages F, Galon J. Natural immunity to cancer in humans. Curr Opin Immunol (2010) 22(2):215-22. doi:10.1016/j. coi.2010.02.006

22. Fridman WH, Mlecnik B, Bindea G, Pages F, Galon J. Immunosurveillance in human non-viral cancers. Curr Opin Immunol (2011) 23(2):272-8. doi:10.1016/j.coi.2010.12.011

23. Teng MW, Swann JB, Koebel CM, Schreiber RD, Smyth MJ. Immunemediated dormancy: an equilibrium with cancer. JLeukoc Biol (2008) 84(4):988-93. doi:10.1189/jlb.1107774 
24. Kim R, Emi $M$, Tanabe $K$. Cancer immunoediting from immune surveillance to immune escape. Immunology (2007) 121(1):1-14. doi:10.1111/j.1365-2567.2007.02587.x

25. Dadi S, Chhangawala S, Whitlock BM, Franklin RA, Luo CT, Oh SA, et al. Cancer immunosurveillance by tissue-resident innate lymphoid cells and innate-like T cells. Cell (2016) 164(3):365-77. doi:10.1016/j.cell.2016. 01.002

26. Smyth MJ, Dunn GP, Schreiber RD. Cancer immunosurveillance and immunoediting: the roles of immunity in suppressing tumor development and shaping tumor immunogenicity. Adv Immunol (2006) 90:1-50. doi:10.1016/ S0065-2776(06)90001-7

27. Galluzzi L, Buque A, Kepp O, Zitvogel L, Kroemer G. Immunological effects of conventional chemotherapy and targeted anticancer agents. Cancer Cell (2015) 28(6):690-714. doi:10.1016/j.ccell.2015.10.012

28. Galon J, Costes A, Sanchez-Cabo F, Kirilovsky A, Mlecnik B, LagorcePages C, et al. Type, density, and location of immune cells within human colorectal tumors predict clinical outcome. Science (2006) 313(5795):1960-4. doi:10.1126/science.1129139

29. Fridman WH, Galon J, Dieu-Nosjean MC, Cremer I, Fisson S, Damotte $D$, et al. Immune infiltration in human cancer: prognostic significance and disease control. Curr Top Microbiol Immunol (2011) 344:1-24. doi:10.1007/82_2010_46

30. Fridman WH, Pages F, Sautes-Fridman C, Galon J. The immune contexture in human tumours: impact on clinical outcome. Nat Rev Cancer (2012) 12(4):298-306. doi:10.1038/nrc3245

31. Galluzzi L, Senovilla L, Zitvogel L, Kroemer G. The secret ally: immunostimulation by anticancer drugs. Nat Rev Drug Discov (2012) 11(3):215-33. doi:10.1038/nrd3626

32. Marzbani E, Inatsuka C, Lu H, Disis ML. The invisible arm of immunity in common cancer chemoprevention agents. Cancer Prev Res (Phila) (2013) 6(8):764-73. doi:10.1158/1940-6207.CAPR-13-0036

33. Teng MW, Galon J, Fridman WH, Smyth MJ. From mice to humans: developments in cancer immunoediting. JClin Invest (2015) 125(9):3338-46. doi:10.1172/JCI80004

34. DuPage M, Mazumdar C, Schmidt LM, Cheung AF, Jacks T. Expression of tumour-specific antigens underlies cancer immunoediting. Nature (2012) 482(7385):405-9. doi:10.1038/nature10803

35. von Boehmer L, Mattle M, Bode P, Landshammer A, Schafer C, Nuber N, et al. NY-ESO-1-specific immunological pressure and escape in a patient with metastatic melanoma. Cancer Immun (2013) 13:12.

36. Balkwill F, Charles KA, Mantovani A. Smoldering and polarized inflammation in the initiation and promotion of malignant disease. Cancer Cell (2005) 7(3):211-7. doi:10.1016/j.ccr.2005.02.013

37. Shrihari TG. Dual role of inflammatory mediators in cancer. Ecancermedicalscience (2017) 11:721. doi:10.3332/ecancer.2017.721

38. Hanahan D, Weinberg RA. Hallmarks of cancer: the next generation. Cell (2011) 144(5):646-74. doi:10.1016/j.cell.2011.02.013

39. Cavallo F, De Giovanni C, Nanni P, Forni G, Lollini PL. 2011: the immune hallmarks of cancer. Cancer Immunol Immunother (2011) 60(3):319-26. doi:10.1007/s00262-010-0968-0

40. Mortaz E, Tabarsi P, Mansouri D, Khosravi A, Garssen J, Velayati A, et al. Cancers related to immunodeficiencies: update and perspectives. Front Immunol (2016) 7:365. doi:10.3389/fimmu.2016.00365

41. Grulich AE, van Leeuwen MT, Falster MO, Vajdic CM. Incidence of cancers in people with HIV/AIDS compared with immunosuppressed transplant recipients: a meta-analysis. Lancet (2007) 370(9581):59-67. doi:10.1016/ S0140-6736(07)61050-2

42. Engels EA, Pfeiffer RM, Fraumeni JF Jr, Kasiske BL, Israni AK, Snyder JJ, et al. Spectrum of cancer risk among US solid organ transplant recipients. JAMA (2011) 306(17):1891-901. doi:10.1001/jama.2011.1592

43. Strauss DC, Thomas JM. Transmission of donor melanoma by organ transplantation. Lancet Oncol (2010) 11(8):790-6. doi:10.1016/ S1470-2045(10)70024-3

44. Bissell MJ, Hines WC. Why don't we get more cancer? A proposed role of the microenvironment in restraining cancer progression. Nat Med (2011) 17(3):320-9. doi:10.1038/nm.2328

45. Nielsen M, Thomsen JL, Primdahl S, Dyreborg U, Andersen JA. Breast cancer and atypia among young and middle-aged women: a study of 110 medicolegal autopsies. Br J Cancer (1987) 56(6):814-9. doi:10.1038/bjc.1987.296
46. Nielsen M. Autopsy studies of the occurrence of cancerous, atypical and benign epithelial lesions in the female breast. APMIS Suppl (1989) 10:1-56.

47. Sakr WA, Haas GP, Cassin BF, Pontes JE, Crissman JD. The frequency of carcinoma and intraepithelial neoplasia of the prostate in young male patients. J Urol (1993) 150(2 Pt 1):379-85.

48. Soos G, Tsakiris I, Szanto J, Turzo C, Haas PG, Dezso B. The prevalence of prostate carcinoma and its precursor in Hungary: an autopsy study. Eur Urol (2005) 48(5):739-44. doi:10.1016/j.eururo.2005.08.010

49. Yin M, Bastacky S, Chandran U, Becich MJ, Dhir R. Prevalence of incidental prostate cancer in the general population: a study of healthy organ donors. J Urol (2008) 179(3):892-5; discussion 895. doi:10.1016/j.juro.2007.10.057

50. Zlotta AR, Egawa S, Pushkar D, Govorov A, Kimura T, Kido M, et al. Prevalence of prostate cancer on autopsy: cross-sectional study on unscreened Caucasian and Asian men. J Natl Cancer Inst (2013) 105(14):1050-8. doi:10.1093/jnci/ djt151

51. Scardino PT. Early detection of prostate cancer. Urol Clin North Am (1989) 16(4):635-55.

52. Folkman J, Kalluri R. Cancer without disease. Nature (2004) 427(6977):787. doi:10.1038/427787a

53. Yachida S, Jones S, Bozic I, Antal T, Leary R, Fu B, et al. Distant metastasis occurs late during the genetic evolution of pancreatic cancer. Nature (2010) 467(7319):1114-7. doi:10.1038/nature09515

54. Eyles J, Puaux AL, Wang X, Toh B, Prakash C, Hong M, et al. Tumor cells disseminate early, but immunosurveillance limits metastatic outgrowth, in a mouse model of melanoma. J Clin Invest (2010) 120(6):2030-9. doi:10.1172/ JCI 42002

55. Manjili MH. The inherent premise of immunotherapy for cancer dormancy. Cancer Res (2014) 74(23):6745-9. doi:10.1158/0008-5472.CAN-14-2440

56. Baxevanis CN, Perez SA. Cancer dormancy: a regulatory role for endogenous immunity in establishing and maintaining the tumor dormant state. Vaccines (Basel) (2015) 3(3):597-619. doi:10.3390/vaccines3030597

57. Imai K, Matsuyama S, Miyake S, Suga K, Nakachi K. Natural cytotoxic activity of peripheral-blood lymphocytes and cancer incidence: an 11-year follow-up study of a general population. Lancet (2000) 356(9244):1795-9. doi:10.1016/S0140-6736(00)03231-1

58. Hayashi T, Imai K, Morishita Y, Hayashi I, Kusunoki Y, Nakachi K. Identification of the NKG2D haplotypes associated with natural cytotoxic activity of peripheral blood lymphocytes and cancer immunosurveillance. Cancer Res (2006) 66(1):563-70. doi:10.1158/0008-5472.CAN-05-2776

59. Chester C, Fritsch K, Kohrt HE. Natural killer cell immunomodulation: targeting activating, inhibitory, and co-stimulatory receptor signaling for cancer immunotherapy. Front Immunol (2015) 6:601. doi:10.3389/ fimmu.2015.00601

60. Nakachi K, Imai K. Environmental and physiological influences on human natural killer cell activity in relation to good health practices. Jpn J Cancer Res (1992) 83(8):798-805. doi:10.1111/j.1349-7006.1992.tb01983.x

61. Imai K, Nakachi K. Personality types, lifestyle, and sensitivity to mental stress in association with NK activity. Int $J$ Hyg Environ Health (2001) 204(1):67-73. doi:10.1078/1438-4639-00075

62. Santos MS, Meydani SN, Leka L, Wu D, Fotouhi N, Meydani M, et al. Natural killer cell activity in elderly men is enhanced by beta-carotene supplementation. Am J Clin Nutr (1996) 64(5):772-7.

63. Couzin-Frankel J. Cancer immunotherapy. Science (2013) 342(6165):1432-3. doi:10.1126/science.342.6165.1432

64. Maresso KC, Tsai KY, Brown PH, Szabo E, Lippman S, Hawk ET. Molecular cancer prevention: current status and future directions. CA Cancer J Clin (2015) 65(5):345-83. doi:10.3322/caac.21287

65. Buchbinder EI, Desai A. CTLA- 4 and PD-1 pathways: similarities, differences, and implications of their inhibition. Am J Clin Oncol (2016) 39(1):98-106. doi:10.1097/COC.0000000000000239

66. Kensler TW, Spira A, Garber JE, Szabo E, Lee JJ, Dong Z, et al. Transforming cancer prevention through precision medicine and immune-oncology. Cancer Prev Res (Phila) (2016) 9(1):2-10. doi:10.1158/1940-6207.CAPR-15-0406

67. Bose S, Panda AK, Mukherjee S, Sa G. Curcumin and tumor immune-editing: resurrecting the immune system. Cell Div (2015) 10:6. doi:10.1186/ s13008-015-0012-z

68. Zitvogel L, Apetoh L, Ghiringhelli F, Kroemer G. Immunological aspects of cancer chemotherapy. Nat Rev Immunol (2008) 8(1):59-73. doi:10.1038/ nri2216 
69. Troen BR. The biology of aging. Mt Sinai J Med (2003) 70(1):3-22.

70. Ongradi J, Kovesdi V. Factors that may impact on immunosenescence: an appraisal. Immun Ageing (2010) 7:7. doi:10.1186/1742-4933-7-7

71. Malaguarnera L, Cristaldi E, Malaguarnera M. The role of immunity in elderly cancer. Crit Rev Oncol Hematol (2010) 74(1):40-60. doi:10.1016/j. critrevonc.2009.06.002

72. Montecino-Rodriguez E, Berent-Maoz B, Dorshkind K. Causes, consequences, and reversal of immune system aging. J Clin Invest (2013) 123(3):958-65. doi:10.1172/JCI64096

73. Bueno V, Sant'Anna OA, Lord JM. Ageing and myeloid-derived suppressor cells: possible involvement in immunosenescence and age-related disease. Age (Dordr) (2014) 36(6):9729. doi:10.1007/s11357-014-9729-x

74. Hurez V, Padron AS, Svatek RS, Curiel TJ. Considerations for successful cancer immunotherapy in aged hosts. Clin Exp Immunol (2017) 187(1):53-63. doi:10.1111/cei.12875

75. Verschoor CP, Johnstone J, Millar J, Dorrington MG, Habibagahi M, Lelic A, et al. Blood CD33(+)HLA-DR(-) myeloid-derived suppressor cells are increased with age and a history of cancer. J Leukoc Biol (2013) 93(4):633-7. doi:10.1189/jlb.0912461

76. Muller L, Pawelec G. Aging and immunity - impact of behavioral intervention. Brain Behav Immun (2014) 39:8-22. doi:10.1016/j.bbi.2013.11.015

77. Bartlett DB, Huffman KM. Lifestyle interventions to improve immunesenescence. In: Bueno V, Lord JM, Jackson TA, editors. The Ageing Immune System and Health. Cham, Switzerland: Springer International Publishing Switzerland (2017). p. 161-76.

78. Davison G, Kehaya C, Jones AW. Nutritional and physical activity interventions to improve immunity. Am J Lifestyle Med (2016) 10(3):152-69. doi:10.1177/1559827614557773

79. Dorshkind K, Montecino-Rodriguez E, Signer RA. The ageing immune system: is it ever too old to become young again? Nat Rev Immunol (2009) 9(1):57-62. doi:10.1038/nri2471

80. Dorak MT, Karpuzoglu E. Gender differences in cancer susceptibility: an inadequately addressed issue. Front Appl Genet Epidemiol (2012) 3:268. doi:10.3389/fgene.2012.00268

81. Clocchiatti A, Cora E, Zhang Y, Dotto GP. Sexual dimorphism in cancer. Nat Rev Cancer (2016) 16(5):330-9. doi:10.1038/nrc.2016.30

82. Klein SL, Flanagan KL. Sex differences in immune responses. Nat Rev Immunol (2016) 16(10):626-38. doi:10.1038/nri.2016.90

83. McTiernan A. Mechanisms linking physical activity with cancer. Nat Rev Cancer (2008) 8(3):205-11. doi:10.1038/nrc2325

84. Handschin C, Spiegelman BM. The role of exercise and PGClalpha in inflammation and chronic disease. Nature (2008) 454(7203):463-9. doi:10.1038/ nature07206

85. Pedersen BK. Exercise-induced myokines and their role in chronic diseases. Brain Behav Immun (2011) 25(5):811-6. doi:10.1016/j.bbi.2011.02.010

86. Goh J, Niksirat N, Campbell KL. Exercise training and immune crosstalk in breast cancer microenvironment: exploring the paradigms of exercise-induced immune modulation and exercise-induced myokines. Am J Transl Res (2014) 6(5):422-38

87. Simpson RJ, Kunz H, Agha N, Graff R. Exercise and the regulation of immune functions. Prog Mol Biol Transl Sci (2015) 135:355-80. doi:10.1016/ bs.pmbts.2015.08.001

88. Gleeson M, Bishop NC, Stensel DJ, Lindley MR, Mastana SS, Nimmo MA. The anti-inflammatory effects of exercise: mechanisms and implications for the prevention and treatment of disease. Nat Rev Immunol (2011) 11(9):607-15. doi:10.1038/nri3041

89. Friedenreich CM. Physical activity and cancer prevention: from observational to intervention research. Cancer Epidemiol Biomarkers Prev (2001) 10(4):287-301.

90. Friedenreich CM, Neilson HK, Lynch BM. State of the epidemiological evidence on physical activity and cancer prevention. Eur J Cancer (2010) 46(14):2593-604. doi:10.1016/j.ejca.2010.07.028

91. Lee IM, Shiroma EJ, Lobelo F, Puska P, Blair SN, Katzmarzyk PT. Effect of physical inactivity on major non-communicable diseases worldwide: an analysis of burden of disease and life expectancy. Lancet (2012) 380(9838):219-29. doi:10.1016/S0140-6736(12)61031-9

92. Calle EE, Thun MJ. Obesity and cancer. Oncogene (2004) 23(38):6365-78. doi:10.1038/sj.onc. 1207751
93. Tilg H, Moschen AR. Adipocytokines: mediators linking adipose tissue, inflammation and immunity. Nat Rev Immunol (2006) 6(10):772-83. doi:10.1038/nri1937

94. Grant RW, Dixit VD. Adipose tissue as an immunological organ. Obesity (Silver Spring) (2015) 23(3):512-8. doi:10.1002/oby.21003

95. Yang H, Youm YH, Vandanmagsar B, Rood J, Kumar KG, Butler AA, et al. Obesity accelerates thymic aging. Blood (2009) 114(18):3803-12. doi:10.1182/ blood-2009-03-213595

96. Philpott M, Ferguson LR. Immunonutrition and cancer. Mutat Res (2004) 551(1-2):29-42. doi:10.1016/j.mrfmmm.2004.03.005

97. Grimble RF. Nutritional modulation of immune function. Proc Nutr Soc (2001) 60(3):389-97. doi:10.1079/PNS2001102

98. Ferguson LR, Philpott M. Cancer prevention by dietary bioactive components that target the immune response. Curr Cancer Drug Targets (2007) 7(5):459-64. doi:10.2174/156800907781386605

99. Song M, Nishihara R, Cao Y, Chun E, Qian ZR, Mima K, et al. Marine omega-3 polyunsaturated fatty acid intake and risk of colorectal cancer characterized by tumor-infiltrating T cells. JAMA Oncol (2016) 2(9):1197-206. doi:10.1001/jamaoncol.2016.0605

100. Talvas J, Garrait G, Goncalves-Mendes N, Rouanet J, Vergnaud-Gauduchon J, Kwiatkowski F, et al. Immunonutrition stimulates immune functions and antioxidant defense capacities of leukocytes in radiochemotherapy-treated head \& neck and esophageal cancer patients: a double-blind randomized clinical trial. Clin Nutr (2015) 34(5):810-7. doi:10.1016/j.clnu.2014.12.002

101. Smith PM, Howitt MR, Panikov N, Michaud M, Gallini CA, Bohlooly YM, et al. The microbial metabolites, short-chain fatty acids, regulate colonic Treg cell homeostasis. Science (2013) 341(6145):569-73. doi:10.1126/ science. 1241165

102. Stampfli MR, Anderson GP. How cigarette smoke skews immune responses to promote infection, lung disease and cancer. Nat Rev Immunol (2009) 9(5):377-84. doi:10.1038/nri2530

103. Ter Horst R, Jaeger M, Smeekens SP, Oosting M, Swertz MA, Li Y, et al. Host and environmental factors influencing individual human cytokine responses. Cell (2016) 167(4):1111-24.e13. doi:10.1016/j.cell.2016.10.018

104. Dorak MT, McNally RJ, Parker L. Re: "Childhood acute lymphoblastic leukemia and infections in the first year of life: a report from the United Kingdom childhood cancer study". Am J Epidemiol (2007) 166(3):364-5. doi:10.1093/ aje/kwm158

105. Urayama KY, Ma X, Selvin S, Metayer C, Chokkalingam AP, Wiemels JL, et al. Early life exposure to infections and risk of childhood acute lymphoblastic leukemia. Int J Cancer (2011) 128(7):1632-43. doi:10.1002/ijc.25752

106. Greaves M. Infection, immune responses and the aetiology of childhood leukaemia. Nat Rev Cancer (2006) 6(3):193-203. doi:10.1038/nrc1816

107. Pinheiro SP, Hankinson SE, Tworoger SS, Rosner BA, McKolanis JR, Finn OJ, et al. Anti-MUC1 antibodies and ovarian cancer risk: prospective data from the Nurses' Health Studies. Cancer Epidemiol Biomarkers Prev (2010) 19(6):1595-601. doi:10.1158/1055-9965.EPI-10-0068

108. Cramer DW, Vitonis AF, Pinheiro SP, McKolanis JR, Fichorova RN, Brown $\mathrm{KE}$, et al. Mumps and ovarian cancer: modern interpretation of an historic association. Cancer Causes Control (2010) 21(8):1193-201. doi:10.1007/ s10552-010-9546-1

109. Balogh GA, Russo IH, Spittle C, Heulings R, Russo J. Immune-surveillance and programmed cell death-related genes are significantly overexpressed in the normal breast epithelium of postmenopausal parous women. Int J Oncol (2007) 31(2):303-12. doi:10.3892/ijo.31.2.303

110. Russo J. Reproductive history and breast cancer prevention. Horm Mol Biol Clin Investig (2016) 27(1):3-10. doi:10.1515/hmbci-2016-0033

111. Agrawal B, Reddish MA, Longenecker BM. In vitro induction of MUC-1 peptide-specific type $1 \mathrm{~T}$ lymphocyte and cytotoxic $\mathrm{T}$ lymphocyte responses from healthy multiparous donors. J Immunol (1996) 157(5):2089-95.

112. Corsini E, Liesivuori J, Vergieva T, Van Loveren H, Colosio C. Effects of pesticide exposure on the human immune system. Hum Exp Toxicol (2008) 27(9):671-80. doi:10.1177/0960327108094509

113. Zhang L, McHale CM, Rothman N, Li G, Ji Z, Vermeulen R, et al. Systems biology of human benzene exposure. Chem Biol Interact (2010) 184(1-2):8693. doi:10.1016/j.cbi.2009.12.011

114. Dangleben NL, Skibola CF, Smith MT. Arsenic immunotoxicity: a review. Environ Health (2013) 12(1):73. doi:10.1186/1476-069X-12-73 
115. Shimizu T, Streilein JW. Local and systemic consequences of acute, low-dose ultraviolet $B$ radiation are mediated by different immune regulatory mechanisms. Eur J Immunol (1994) 24(8):1765-70. doi:10.1002/eji.1830240807

116. Kiecolt-Glaser JK, Robles TF, Heffner KL, Loving TJ, Glaser R. Psychooncology and cancer: psychoneuroimmunology and cancer. Ann Oncol (2002) 13 Suppl 4:165-9. doi:10.1093/annonc/mdf655

117. Reiche EM, Nunes SO, Morimoto HK. Stress, depression, the immune system, and cancer. Lancet Oncol (2004) 5(10):617-25. doi:10.1016/ S1470-2045(04)01597-9

118. Brodin P, Jojic V, Gao T, Bhattacharya S, Angel CJ, Furman D, et al. Variation in the human immune system is largely driven by non-heritable influences. Cell (2015) 160(1-2):37-47. doi:10.1016/j.cell.2014.12.020

119. Roederer M, Quaye L, Mangino M, Beddall MH, Mahnke Y, Chattopadhyay $\mathrm{P}$, et al. The genetic architecture of the human immune system: a bioresource for autoimmunity and disease pathogenesis. Cell (2015) 161(2):387-403. doi:10.1016/j.cell.2015.02.046

120. Orru V, Steri M, Sole G, Sidore C, Virdis F, Dei M, et al. Genetic variants regulating immune cell levels in health and disease. Cell (2013) 155(1):242-56. doi:10.1016/j.cell.2013.08.041

121. Perez-Losada J, Castellanos-Martin A, Mao JH. Cancer evolution and individual susceptibility. Integr Biol (Camb) (2011) 3(4):316-28. doi:10.1039/ c0ib00094a

122. Le Marchand L. The predominance of the environment over genes in cancer causation: implications for genetic epidemiology. Cancer Epidemiol Biomarkers Prev (2005) 14(5):1037-9. doi:10.1158/1055-9965.EPI-04-0816

123. Vajdic CM, van Leeuwen MT. Cancer incidence and risk factors after solid organ transplantation. Int J Cancer (2009) 125(8):1747-54. doi:10.1002/ ijc. 24439

124. Koebel CM, Vermi W, Swann JB, Zerafa N, Rodig SJ, Old LJ, et al. Adaptive immunity maintains occult cancer in an equilibrium state. Nature (2007) 450(7171):903-7. doi:10.1038/nature06309

125. Teng MW, Vesely MD, Duret H, McLaughlin N, Towne JE, Schreiber RD, et al. Opposing roles for IL-23 and IL-12 in maintaining occult cancer in an equilibrium state. Cancer Res (2012) 72(16):3987-96. doi:10.1158/00085472.CAN-12-1337

126. Shankaran V, Ikeda H, Bruce AT, White JM, Swanson PE, Old LJ, et al. IFNgamma and lymphocytes prevent primary tumour development and shape tumour immunogenicity. Nature (2001) 410(6832):1107-11. doi: $10.1038 / 35074122$

127. Darnell RB, Posner JB. Observing the invisible: successful tumor immunity in humans. Nat Immunol (2003) 4(3):201. doi:10.1038/ni0303-201

128. Wojtowicz ME, Dunn BK, Umar A. Immunologic approaches to cancer prevention - current status, challenges, and future perspectives. Semin Oncol (2016) 43(1):161-72. doi:10.1053/j.seminoncol.2015.11.001

129. Siegel RL, Miller KD, Jemal A. Cancer statistics, 2016. CA Cancer J Clin (2016) 66(1):7-30. doi:10.3322/caac.21332

130. McTiernan A, Schwartz RS, Potter J, Bowen D. Exercise clinical trials in cancer prevention research: a call to action. Cancer Epidemiol Biomarkers Prev (1999) 8(3):201-7.

131. McTiernan A. Intervention studies in exercise and cancer prevention. Med Sci Sports Exerc (2003) 35(11):1841-5. doi:10.1249/01. MSS.0000093749.90499.63

132. Winzer BM, Whiteman DC, Reeves MM, Paratz JD. Physical activity and cancer prevention: a systematic review of clinical trials. Cancer Causes Control (2011) 22(6):811-26. doi:10.1007/s10552-011-9761-4
133. Sumamo E, Ha C, Korownyk C, Vandermeer B, Dryden DM. Lifestyle Interventions for Four Conditions: Type 2 Diabetes, Metabolic Syndrome, Breast Cancer, and Prostate Cancer. 2014/12/05 ed. Rockville, MD, USA: Agency for Healthcare Research and Quality (US) (2011) May 26 Breast Cancer, and Prostate Cancer.

134. Toft UN, Kristoffersen LH, Aadahl M, von Huth Smith L, Pisinger C, Jorgensen T. Diet and exercise intervention in a general population - mediators of participation and adherence: the Inter99 study. Eur J Public Health (2007) 17(5):455-63. doi:10.1093/eurpub/ckl262

135. Busch C, Burkard M, Leischner C, Lauer UM, Frank J, Venturelli S. Epigenetic activities of flavonoids in the prevention and treatment of cancer. Clin Epigenetics (2015) 7:64. doi:10.1186/s13148-015-0095-Z

136. Harris Z, Donovan MG, Branco GM, Limesand KH, Burd R. Quercetin as an emerging anti-melanoma agent: a four-focus area therapeutic development strategy. Front Nutr (2016) 3:48. doi:10.3389/fnut.2016.00048

137. Fujiki H, Sueoka E, Watanabe T, Suganuma M. Primary cancer prevention by green tea, and tertiary cancer prevention by the combination of green tea catechins and anticancer compounds. J Cancer Prev (2015) 20(1):1-4. doi:10.15430/JCP.2015.20.1.1

138. Cuevas A, Saavedra N, Salazar LA, Abdalla DS. Modulation of immune function by polyphenols: possible contribution of epigenetic factors. Nutrients (2013) 5(7):2314-32. doi:10.3390/nu5072314

139. Mentz RJ, Hernandez AF, Berdan LG, Rorick T, O’Brien EC, Ibarra JC, et al. Good clinical practice guidance and pragmatic clinical trials: balancing the best of both worlds. Circulation (2016) 133(9):872-80. doi:10.1161/ CIRCULATIONAHA.115.019902

140. Ford I, Norrie J. Pragmatic trials. N Engl J Med (2016) 375(5):454-63. doi:10.1056/NEJMra1510059

141. Luke DA, Stamatakis KA. Systems science methods in public health: dynamics, networks, and agents. Annu Rev Public Health (2012) 33:357-76 doi:10.1146/annurev-publhealth-031210-101222

142. Puska P, Vartiainen E, Tuomilehto J, Salomaa V, Nissinen A. Changes in premature deaths in Finland: successful long-term prevention of cardiovascular diseases. Bull World Health Organ (1998) 76(4):419-25.

143. Townsend N, Wilson L, Bhatnagar P, Wickramasinghe K, Rayner M, Nichols M. Cardiovascular disease in Europe: epidemiological update 2016. Eur Heart J (2016) 37(42):3232-45. doi:10.1093/eurheartj/ehw334

144. Vineis P, Wild CP. Global cancer patterns: causes and prevention. Lancet (2014) 383(9916):549-57. doi:10.1016/S0140-6736(13)62224-2

145. Colditz GA, Wolin KY, Gehlert S. Applying what we know to accelerate cancer prevention. Sci Transl Med (2012) 4(127):127rv4. doi:10.1126/ scitranslmed.3003218

Conflict of Interest Statement: The authors declare that the research was conducted in the absence of any commercial or financial relationships that could be construed as a potential conflict of interest.

Copyright (c) 2017 Singh and Dorak. This is an open-access article distributed under the terms of the Creative Commons Attribution License (CC BY). The use, distribution or reproduction in other forums is permitted, provided the original author(s) or licensor are credited and that the original publication in this journal is cited, in accordance with accepted academic practice. No use, distribution or reproduction is permitted which does not comply with these terms. 